\title{
RHYNCHOTA ETHIOPICA
}

\author{
descripsit E. Bergroth.
}

V

Fam. PENTATOMIDA.

\section{Tessaratoma spinipes n, sp.}

Ovalis, luride ochracea, dorso abdominis concolore, corio remote subreticulatim fusco-marmorato, antennis fuscis, articulo primo apice excepto corpori concolore, fascia postica curvata mesosterni prope acetabula et fascia metasterni orificia cingente extusque prolongata fuliginose fuscis. Caput longitudine dimidio latius, vermiculato-rugosum, vix punctatum, lateribus ante oculos distincte sinuatum, apice late rotundatum, bucculis antice rotundatis, rostro medium mesosterni haud attingente, apicem versus infuscato, antennis brevibus, angulos laterales pronoti subattingentibus, articulo primo apicem capitis paullum superante, secundo tertio tertia parte longiore, quarto secundo distinctissime longiore. Pronotum usque ad margines laterales minute modice dense, pone medium remotius, subfusco-punctulatum, parte apicali (ante cicatrices) multo fortius punctatum, marginibus lateralibus anticis leviter rotundatis, apicem versus subrectis. Scutellum remote subfusco-punctatum, basi fere impunctatum, parte pone frena sita remotissime punctata, latiuscula, leviter excavata, frenis distincte ultra medium scutelli extensis. Corium sat dense subconcoloriter punctulotum, margine apicali late rotundato; clavus minus dense fusco-punctulatus; membrana hyalina, levissime in testaceum vergens. Alæ violascentes. Pectus remote subfusco-punctatum, carina mesosterni medium coxarum anticarum superante, elevatione sternali transversim leviter convexa, remotissime minute punctulata, coxas anticas attingente, basi recta, antice paullo magis elevata, apice e latere visa æqualiter fortiter rotundata. Abdomen subtus dense minutissime punctulatum, extra spiracula minute remote aciculato - punctulatum, elevatione media remotissime minute punctulata, angulis apicalibus segmentorum nonnihil prominulis, rectis, angulis segmenti sexti acutis. Pedes breves, femoribus omnibus subtus prope apicem spinis duabus validis, una utrinque, oblique apicem versus directis armatis, tibiis femoribus multo brevioribus, rectis. - Long. o 19,5 mill. - q 20,5 mill. 
Mas. : segmentum genitale longitudine distincte latius, apice profunde subrectangulariter emarginatum.

Femina : lobi genitales laterales (stigmatiferi) margine externo subrecti; lobi apicales intus e basi per duas trientes longitudinis contigui, deinde fortiter divaricati, inter se angulum rectum formantes.

Africa orientalis (insula Pemba).

Parva in hoc genere. T. Afzelii Stål similis, sed minor et femoribus spinigeris, segmentis genitalibus omnino aliter constructis variisque aliis notis distinctissima.

\section{Sepina conjungens n. sp.}

Oblongo ovalis, fusca, capite subtus et ante medium superne, rostro, articulis tribus primis antennarum, marglne apicali pronoti, marginibus lateralibus prothoracis, mesosterni coriique, epipleuris, villa lata media ventris limboque abdominis ac pedibus testaceis, his pallide fusco-conspersis, annulo lato apicali articuli quarti antennarum, apice scutelli ac macula postmediana corii secundum venam medianam antrorsum lineariter continuata albidis, segmentis connexivi supra et subtus ad marginem basalem et apicalem anguste et diffuse infuscatis. Caput longitudine paullulo latius, supra dense punctulatum, basi et area utrinque intraoculari impunctatum, lateribus reflexis, ante oculos fortius sinuatis, deinde usque ultra medium jugorum parallelis, ibi obtuse angulatis, jugis ante hunc angulum oblique truncatis, tylo vix longioribus, apice nonnihil approximatis sed distantibus, ocellis inter se quam ab oculis minus quam triplo longius distantibus, bucculis antice subrectangulatis, rostro apicem segmenti tertii ventris attingente, articulo primo medium prosterni subattingente, secundo duobus ultimis unitis breviore, his subæque longis, antennis capiti, pronoto scutelloque unitis æque longis, parce breviter setulosis, articulo primo apicem capitis vix superante, secundo latitudini capitis saltem æque longo, tertio primo paullo longiore, quarto secundo paullo breviore, quinto secundo duplo breviore, apice dilutiore. Pronotum longitudine media paullo plus quam duplo latius, inter angulos laterales quam apice duplo et dimidio latius, sat dense punctulatum, marginibus lateralibus subrectis, anguste laminatoreflexis, angulis apicalibus obtusis, non prominulis, angulis lateralibus ob margines laterales ibidem subito abruptos leviter angulato-sinuatis. Scutellum planiusculum, latitudine paullo brevius, transversim leviter rugulosum et disperse punctatum. Pectus sparsim punctulatum, propleuris pone medium fortius punctatis, vitta externa semilunata metapleurarum lævi, meso- 
sterno profunde sulcato, area evaporaliva medium metapleuræ haud altingente, sed etiam aream majusculam triangularem mesopleuræ occupante, angulis posticis metastethii productis, acutis. Corium sat dense punctulatum, margine apicali late leviter sinuato; membrana saturate fusca, prope angulum basalem interiorem cellulis duabus oblongis instructa, cellula exteriore interiore multo breviore et plus quam duplo angustiore. Alæ violaceæ. Abdomen subtus usque ad apicem segmenti quarti late leviter sulcatum, subtiliter irregulariter striolatum, solum intra spiracula ante medium segmentorum per aream haud magnam punctis raris præditum, connexivo supra et subtus lævi, segmentis omnibus ventralibus intra spiracula impressione transversa media sat profunda instructis, angulis apicalibus nonnihil prominulis, subacutis, segmento sexto ventrali feminæ medio quinto tertia parte longiore, retrorsum producto, valvulas genitales basales fere totas obtegente, segmento genitali dorsali primo feminæ margine apicali late levissime rotundato, augulis apicalibus triangulariter productis, segmento genitali dorsali secundo primo multo angustiore, angulis apicalibus subacute lobato-productis. - Long. o 11,5 mill.

\section{- Ins. Comoro (Moheli Miremari).}

Species inter genera Sepina Sign. et Pisena Horv., quæ in unum conjungenda sunt, exacte intermedia. S. urolabidoidi Sign. proxima, sed differt capite aliter et fere ut in longirostri Horv. constructo (etsi juga apice haud contigua sunt), ocellis multo minus distantibus, rostro longiore, antennis aliter coloratis, pronoto et scutello linea media pallida destitutis, illo lateribus acutius reflexo, mesosterno profundius sulcato, membrana obscuriore, ventre sulcato, segmento sexto ventrali feminæ retrorsum longius producto, valvulis genitalibus basalibus maxima parte occultis. Etiam P. Horvathi Schout. et aberrans Schout. quodammodo transitiones inter illa genera formant.

Fam. PYRRHOCORIDÆ.

\section{Callibaphus gigas n. sp.}

Totus impunctatus, sanguineus, antennis (basi excepta), macula media rotundata corii, membrana, vitta brevi basali exteriore femorum anticorum, dimidio basali femorum mediorum, parte basali plus quam dimidia femorum posticorum, tibiis et tarsis omnibus (exceptis illarum et macula apicali supera) nigris, spiraculis albidis, angustissime nigromarginatis. Rostrum medium segmenti quinti ventralis superans. Lobus anticus pronoti, scutel- 
lum, caput subtus, pectus segmentaque genitalia pilis longiusculis crispulis adpressis ochraceis modice dense vestita. Antennæ et pronotum ut in C. longirostri constructa femoraque antica eodem modo armata. - Long. $q 31$ mill.

Ins. Comoro (Anjonan).

C. longirostri Drury Guineam habitanti valde affinis videtur, sed longe aliter coloratus. An ejus varietas geographica? Genus Callibaphus Stål, cujus species adhuc unica etiam in Africa occidentali rarissima est, in Africa orientali hauddum inventum est. Segmenta genitalia feminina sat complicata formæ comorensis illis speciei guineensis comparare nunc nequeo.

Maxima, ni fallor, inter Pyrrhocoridas est hæc forma, excepta Macrocercea grandi Gray, cujus mas abdomen abnormaliter prolongatum habet.

\section{Adherris nov. gen.}

Corpus e medio abdominis antrorsum et retrorsum angustatum. Caput fere usque ad oculos immersum, subtriangulare, apice pronoti latius sed basi ejus nonnihil angustius, superne arcuatodeclive, tylo ante juga prominente, gula transversim fortiter et longitudinaliter leviter convexa, bucculis brevibus, leviter rotundatis, totis ante tubercula antennifera sitis, oculis sessilibus, magnis, globosis, fortiter prominulis, antrorsum divergentibus, rostro basin ventris attingente, articulo primo apicem prosterni attingente, secundo primo æquilongo, tertio secundo quarta parte breviore, quarto tertio tertia parte breviore, antennis ab apice capitis quam ab oculis paullo longius insertis, articulo primo plus quam dimidio suo apicem capitis superante, tertio adjacentibus breviore. Pronotum trapezoideum, transversum, horizontale, apicem versus leviter angustatum, apice parum sinuatum, collari destitutum, lateribus anguste marginatum; basi ante scutellum latissime et levissime sinuatum, disco haud impressum. Scutellum planum, latittudine paullo longius. Metasternum impressione longitudinali media fusiformi instructum, angulis posticis subacutis, orificiis distinctis, elongatis, levissime curvatis, anguste calloso-marginatis. Hemelytra abbreviata, incompleta, apicem segmenti antepenultimi abdominis subattingentia, corio et clavo subconnatis, commissura hujus scutello nonnihil longiore, illo margine costali leviter rotundato, angulo apicali exteriore late rotundato, margine apicali suboblique truncato; membrana nulla. Abdomen hemelytris haud latius, segmentis dorsalibus quarto et quinto basi sinuatis, sinu medio profundiore et lobulo segmenti præcedentis repleto, segmento ultimo dorsali 
maris apice levissime rotundato, connexivo angusto, reflexo, suturis ventralibus tertia et quarta lateribus antrorsum fortiter curvatis, segmento ultimo ventrali maris apice truncato; genitalia mascula apicem abdominis normaliter haud vel vix superantia (interdum autem, forsan post copulam, plus minusve producta), segmentis tribus composita, segmento primo normaliter sub segmento ultimo ventrali occulto, segmentis duobus ultimis perpen-

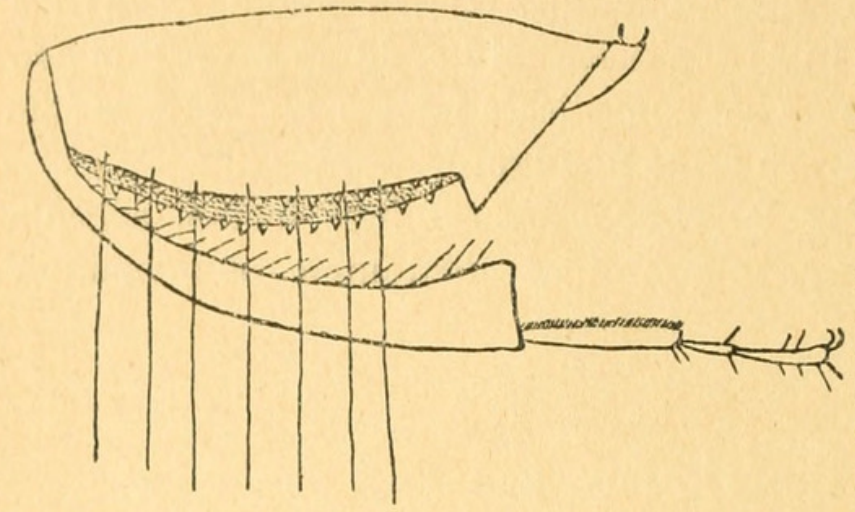

Fig. 1. diculariter reflexis, secundo tertio longiore, apice medio ad apicem impresso. Pedes antici contigui, femoribus incrassatis, nonnihil compressis, subtus quam supra longitudinaliter multo magis convexis, basi late oblique truncatis, subtus cristis duabus

parallelis, sulcum inter se includentibus, per totam longitudinem serie spinularum minutarum armatis instructis, crista anteriore prope basin in tuberculum spiniforme elevata, femoribus subtus præterea paullo extra cristam anteriorem serie pilarum paucarum longissimarum præditis, tibiis (saltem in mare) fortiter curvatis, apice dilatatis, subtus serie setularum oblique apicem versus directarum, e granulis minutissimis nascentium præditis (vide fig., in qua pes dexter anticus paullo oblique ab antico visus delineatus est); pedes posteriores leviter distantes, articulo primo tarsorum posticorum articulis apicalibus unitis duplo longiore.

Generi Dermatinus Stål affinis, at structura pedum anticorum mox distincta.

\section{Aderrhis pulla n. sp.}

Pyriformis. opacula, nigra, pube subtilissima brevissima adpressa albida sat dense et in ventre densius vestita, notula transversa occipitali, apice scutelli, articulis tribus ultimis rostri pedibusque rufovel flavo-testaceis, apice femorum fusco-nigro, tibiis et tarsis nonnihil infuscatis, pronoto pone medium et hemelytris sat dense punctatis, punctis plus minusve distincte cinereo-cinctis. Caput longitudine paullo latius et altitudine perpaullo longius, antennis apicem scutelli nonnihil superantibus, articulo primo interdum testaceo-tincto, secundo primo dimidio longiore, tertio primo fere æque longo, quarto secundo subæquali. Pronotum subæque 
longum ac apice latum, basi quam apice plus quam dimidio latius, marginibus lateralibus subrectis, ad angulos apicales rotundatis. Pilæ seriatæ femorum anticorum altitudine femorum longiores. Segmentum sextum ventrale maris medio segmentis duobus præcedentibus unitis parum brevius. (Femella ignota.) - Long. $\sigma^{7}$ 5-5,5 mill.

A frica orientalis (ins. Pemba).

Inter Pyrrhocoridas minimas cognitas, Halticaria quædam brachyptera inter Miridas subsimulans.

Fam. REDUVIID E.

Margasus princeps n. sp.

Cærulescenti-niger, articulo primo antennarum, corio pedibusque saturate purpureis, articulis tribus ultimis antennarum ferrugineotestaceis, membrana nonnihil infuscata, leviter ænescente et violascente, alis infuscatis, abdomine nitidissimo, supra cæruleo, subtus æneo, hic et illic cupreo-resplendente, spiraculıs albis, parte anteoculari capitis basique partis postocularis superioris, vittis duabus gularibus postice confluentibus, lineis compluribus subreticulatis lobi antici pronoti, impressione pronoti transversa marginibusque lateralibus posticis, dimidio apicali scutelli, pectore toto, coxis, clavo ac corio, excepta parte hujus apicali prolongata, dense adpresse albo - ochraceo - pubescentibus. Caput pronoto æque longum, articulo primo antennarum capite et pronoto unitis paullo longiore, secundo primo plus quam duplo breviore, tertio nonnihil variabili, secundo circiter duplo breviore. Pronotum ab apice ultra medium parce erecte decoloriter pilosum, angulis apicalibus oblique truncatis, tuberculis duobus lobi antici humilibus, obtusis, lobo postico dense rugoso-punctato, tuberculis duobus mediocribus, apice lævibus, angulis lateralibus breviter triangulariter dentatoeminentibus. Scutellum in dimidio basali area magna transversa subimpressa præditum, in dimidio apicali elevatione transversa curvata ad apicem humilius continuata instructum, dimidio scutelli apicali præter pubescentiam adpressam longe erecte albido-piloso. Abdomen lateribus nonnihil rotundato-ampliatum, spiraculis ( $(q)$ segmentorum quarti et quinti a margine laterali quam ab apicali paullo longius distantibus, ventre parce sed sat longe albido-piloso. Pedes erecte albido-pilosi. - Long. +25 mill.

Africa orientalis (ins. Pemba).

M. opulenta Dist. subaffinis videtur, sculptura pronoti insignis. 


\section{Petalochirus vittiventris n. sp.}

Elongato-ovatus, supra fuscus, subtus niger, fascia capitis plus minusve distincta ocellos includente, clypeo interdum inferius, lobo antico pronoti medio, vittis tribus et plerumque spinis lobi ejus postici, maculis nonnullis scutelli, maculis numerosis irregularibus hemelytrorum, macula transversa media segmentorum dorsalium abdominis, fascia lata subbasali segmentorum connexivi supra et subtus, dimidio apicali spinarum abdominis, limbo acetabulorum, maculis nonnullis lateralibus pectoris, spiraculis ac vitta media ventris e basi segmenti secundi ad basin segmenti sexti tracta sæpe medio interrupte fuscolineata ochraceis, macula obliqua apicem mesocorii occupante fuliginosa, antennis fusconigris, articulo primo medio late et annulo anteapicali articuli secundi ochraceis, coxis fusconigris, apice cum trochanteribus ochraceis, femoribus fuscis, annulo lato subbasali et annulo pone medium ochraceis, tibiis anticis fuscis, fascia media ochracea notatis, tibiis posterioribus ochraceis, basi, annulo ante medium apiceque fuscis, tarsis ochraceis, articulo ultimo fusco. Caput inerme, ochraceosericeum, tylo inter antennas acute carinato-elevato, articulo primo antennarum capite nonnihil longiore, secundo primo paullo minus quam duplo longiore, tertio et quarto brevibus, longitudine variabilibus. Pronotum linea longitudinali media profunde impressa percurrente præditum, ochraceo-sericeum, lobo antico inermi, utrinque vittis tribus glabris prædito, vitta intima antice plerumque furcata, extima brevissima vel rotundata, angulis apicalibus oblique truncatis, parte truncata extus prominula, angulis lateralibus lobi postici spina valida extus, sursum retrorsumque directa armatis. Scutellum in medio laterum spina brevi nigra et apice spina longa leviter recurva armatum, postscutello apice etiam in spinam oblique ascendentem producto. Hemelytra abdomine paullo breviora, membrana cellulis tribus basalibus completis instructa. Abromen ad angulos apicales segmentorum, ultimo excepto, spina semierecta armatum, ventre inter spiracula et marginem lateralem carina instructo, hac carina in segmento quinto ad spiraculum currente et ibidem subito abrupta. Femora antica basin versus nonnihil curvata. - Long. o 13 mill. - $q$ 14,5-15,5 mill.

Mas : tibiæ anticæ subtus levissime lineariter dilatatæ, superne e basi per duas trientes tibiæ sensim modice rotundato-dilatatæ, parte dilatata trientis apicalis subparallela; segmenfum genitale primum subtriangulare, lobuliforme, apice obtusum, medium segmenti genitalis secundi globoso-convexi haud attingens; styli genitales depressi. 
Femina : tibiæ anticæ subtus nonnihil rotundato-dilatatæ, superne e basi per longitudinem fere totam rotundatim late laminatoampliatæ.

Africa orientalis (ins. Pemba).

Inter $P$. rubiginosum P. B., cui pictura ventris subsimilis est, et $P$. Murrayi Sign. quasi intermedius; differt ab illo magnitudine minore et scutello lateribus spina armato, ab hoc lobo antico pronoti inermi. 


\section{$2 \mathrm{BHL}$ Biodiversity Heritage Library}

Bergroth, Ernest Evald. 1906. "Rhynchota Aethiopica V." Annales de la Société entomologique de Belgique 50, 196-203. https://doi.org/10.5962/bhl.part.19945

View This Item Online: $\underline{\text { https://www.biodiversitylibrary.org/item/46136 }}$

DOI: https://doi.org/10.5962/bhl.part.19945

Permalink: https://www.biodiversitylibrary.org/partpdf/19945

\section{Holding Institution}

Smithsonian Libraries

\section{Sponsored by}

Smithsonian

\section{Copyright \& Reuse}

Copyright Status: NOT_IN_COPYRIGHT

This document was created from content at the Biodiversity Heritage Library, the world's largest open access digital library for biodiversity literature and archives. Visit BHL at https://www.biodiversitylibrary.org. 